\title{
Spontaneous abortion in dry cleaning workers potentially exposed to perchloroethylene
}

\author{
Pat Doyle, Eve Roman, Valerie Beral, Marion Brookes
}

Epidemiology Unit, Department of Epidemiology and Population Health, London School of Hygiene and Tropical Medicine, Keppel Street, London, UK P Doyle

M Brookes

Leukaemia Research Fund, Centre for Clinical Epidemiology at Leeds University, 17 Springfield Mount, Leeds, UK

E Roman

Cancer Epidemiology Unit, Imperial Cancer Research Fund, Gibson

Building, The

Radcliffe Infirmary, Oxford, UK

V Beral

Correspondence to: Dr P Doyle, Epidemiology Unit, Department of Epidemiology and Population Health, London School of Hygiene and Tropical Medicine, Keppe Street, WC1E 7HT, UK.

Accepted 11 September 1997

\begin{abstract}
Objectives-To investigate the association between spontaneous abortion and work within dry cleaning units in the United Kingdom where the solvent perchloroethylene is used.

Methods-A retrospective occupational study of reproductive outcome in 7305 women aged 16 and 45 years, who were currently or previously employed in dry cleaning or laundry units in the United Kingdom. Data on workplace exposures and reproductive outcome were obtained by postal survey. A sample of reported spontaneous abortions was validated from medical records. Machine operator versus non-operator was used as a surrogate for exposure to perchloroethylene in dry cleaning units as no data on individual doses were available for women in this study.
\end{abstract}

Results-The response rate was higher for current workers of dry cleaning units (78\%), than for past workers of dry cleaning units $(46 \%)$. Similarly, the response for current laundry workers $(65 \%)$ was higher than that for past laundry workers $(40 \%)$. Overall, the reproductive characteristics of the respondents were similar to expectation. Examination of exposure at the time of pregnancy, however, showed that the rate of spontaneous abortion varied according to the type of work the women did during the pregnancy or in the three months before conception: being lowest for pregnancies not exposed to either dry cleaning or laundry work (10.9\%), higher for those exposed to laundry work (13.4\%), and higher still for those exposed to dry cleaning work (14.8\%). Within the group of pregnancies exposed to dry cleaning, the proportion was higher if the woman reported that she worked as an operator at the time of the pregnancy $(17.1 \%)$ rather than as a non-operator (11.6\%). Adjusted odds ratios for the period 1980-95 showed that the risk was over $50 \%$ higher in operators than nonoperators $(p=0.04)$. The physical demands of the two jobs are likely to be similar. A higher risk was found when work as a dry cleaning operator was compared with no work in either dry cleaning or laundry units during pregnancy. Exposure to dry cleaning as a non-operator was not associated with any excess risk.

Conclusions-Women who worked in dry cleaning shops at the time of their preg- nancy or in the three months before who described themselves as operators were about half as likely again to report that their pregnancy ended in a spontaneous abortion than women who described themselves as non-operators.

\section{(Occup Environ Med 1997;54:848-853)}

Keywords: spontaneous abortion; dry cleaning; perchloroethylene

Perchloroethylene, also known as tetrachloroethylene, is a colourless organic compound (alkyl halide) which has been used as an industrial solvent for over 50 years, and as a dry cleaning agent for over 30 years. An important source of human exposure to perchloroethylene is through its use in dry cleaning units, and there has been considerable interest in its possible adverse reproductive effects, especially on spontaneous abortion.

The first report which caused concern was published in 1980 by Hemminki et al who linked 9000 female members of the Union of Chemical Workers in Finland to pregnancies registered as occurring between 1973 and 1976. As a whole, this group of workers showed an increased risk of spontaneous abortion compared with the general population, with laundry workers and dry cleaners combined being about twice as likely to miscarry. Although subsequent publications from the same researchers have reported similar results, the findings are difficult to interpret because subjects from the initial study were included. ${ }^{2-4}$ A later case-control study from Finland reported an increased odds ratio for exposure to perchloroethylene which was estimated to be high according to the employer's classification and a limited number of blood concentrations obtained supported the classification of the high exposure subjects. ${ }^{5}$ In an attempt to bring the many Scandinavian studies together, Olsen et al pooled data from Sweden, Denmark, and Finland. ${ }^{6}$ Despite problems of low response and possible misclassification, the pooled results showed a trend of increasing spontaneous abortion risk with increasing exposure to perchloroethylene.

There have been few studies from nonScandinavian countries. An Italian cohort study of 67 dry cleaning workers yielded a risk of spontaneous abortion four times that of a comparison group of housewives, but the numbers were small and the result non-significant. ${ }^{7}$ Outside Europe, a large Californian case-control study found a significantly 
increased risk for spontaneous abortion associated with occupational exposure to perchloroethylene, ${ }^{8}$ but a large Canadian crosssectional study found no evidence of such an association. ${ }^{910}$ This study was not, however, set up to specifically investigate the relation between spontaneous abortion and solvent exposure.

In summary, published studies of spontaneous abortion in dry cleaners provide some evidence of an increased risk which could be related to exposure to perchloroethylene in the workplace. We report here the results of the first study of spontaneous abortion and perchloroethylene to be undertaken in the United Kingdom.

\section{Subjects and methods}

This was a retrospective occupational cohort study of the pregnancies of women who currently work or used to work in dry cleaning or laundry units. Laundry workers in the companies surveyed were not exposed to perchloroethylene. The main source of study participants was a large company managing 696 dry cleaning shops and 13 laundry units throughout the United Kingdom. The initial study population comprised all female workers aged between 16 and 45 at the time of the survey who were working, or had worked, in dry cleaning shops or laundry units managed by this company. As the number of laundry workers in this initial cohort was low, additional laundry workers were subsequently recruited from three other companies. Date of birth, work address of employed people, and last known home address of leavers was supplied to the study team from the companies involved. The shop or laundry category of past workers referred to their last period of employment.

Data on workplace exposure and reproductive outcome were obtained by postal survey with methods developed by authors in other studies. ${ }^{11}$ Name and address labels which included bar code identification numbers were prepared for each study participant. Letters containing a survey form, an information leaflet, a covering letter from the study team, and a reply paid envelope were sent to 7113 employees of the first company during one week in October 1995. Two reminders were sent during the period November 1995 to February 1996, and further follow up of current workers who had left employment since the computer download was attempted after that date. An extra 192 laundry workers from a further three companies were surveyed between April and July 1996. A free telephone line was set up to take calls from study participants.

A pregnancy was considered confirmed, and included in the study, if it was recorded on the form as having ended in a live birth, had been confirmed by a doctor, or hospital treatment had been required. Spontaneous abortion was defined as any fetal loss before 28 weeks of gestation occurring in a confirmed pregnancy. Pregnancies with estimated conception dates of less than 40 weeks before the date of the survey were excluded: this was to avoid truncation effects resulting from the fact that pregnancies with a shorter duration would be more likely to be included than pregnancies with a longer duration. To check the reliability of self reported fetal loss, a sample of reported spontaneous abortions was followed up. All women reporting a spontaneous abortion who said that they worked in dry cleaning shops or laundries during the pregnancy, and a random sample of 58 women reporting fetal losses who said that they did not work in a dry cleaners or in a laundry during the pregnancy, were asked for details of their general practitioner (GP) and permission to access medical records. Once permission was obtained the GP was contacted and asked whether or not there was documentary evidence of fetal loss.

To assess exposure, for each pregnancy the participant was asked if she was working in a laundry or a dry cleaning shop at any time during the pregnancy or in the three months before the pregnancy began. If she answered yes to the dry cleaning shop question, she was asked if she was an operator. Perchloroethylene air sampling data gathered by the company were available, but could not be used in this study because they were collected for shop units rather than people. Also, the data on shop exposure did not contain sufficient information to permit linkage to pregnancies reported at survey.

In the analyses that follow, the unit of observation is a pregnancy. Pregnancies were classified as having occurred before, during, or after work in a laundry or dry cleaning shops. The unadjusted rate of spontaneous abortions was calculated as the number of reported spontaneous abortions divided by the number of livebirths, spontaneous abortions, and stillbirths. Ectopic and molar pregnancies, as well as medical terminations, were excluded from the denominator. Rates in different groups were compared with a ratio of the rate in the exposed group divided by the rate in the unexposed group. Odds ratios were computed with standard unconditional logistic regression methods and software, ${ }^{12}{ }^{13}$ and two sided $\mathrm{p}$ values and $95 \%$ confidence intervals (95\% CIs) are presented throughout. Where appropriate, maternal age, pregnancy order, and year of event were treated as confounders and adjusted for in the models. To account for possible lack of independence among women who experienced more than one pregnancy, separate analyses restricted to first and last pregnancies only were performed.

\section{Results}

\section{RESPONSE RATES}

Table 1 shows details of the response rates. Overall, $21.5 \%$ of the questionnaires sent out were returned as undelivered. The figure was highest for those who were categorised as current employees of dry cleaning shops at the time of the survey $(30.9 \%)$. Staff turnover is high in this industry, which may explain the high proportion of undelivered packages. Of the $\mathbf{5 7 1 2}$ forms which were not sent back undelivered, $54.5 \%$ were sent back completed. There was a considerable difference between current and past employees: for current dry 
Table 1 Response ( $n(\%))$ to postal questionnaire by employment status at time of survey

\begin{tabular}{|c|c|c|c|c|c|}
\hline & \multicolumn{2}{|c|}{ Dry cleaning shop } & \multicolumn{2}{|l|}{ Laundry } & \multirow[b]{2}{*}{ Total } \\
\hline & $\begin{array}{l}\text { Current } \\
\text { worker }\end{array}$ & $\begin{array}{l}\text { Past } \\
\text { worker }\end{array}$ & $\begin{array}{l}\text { Current } \\
\text { worker }\end{array}$ & $\begin{array}{l}\text { Past } \\
\text { worker }\end{array}$ & \\
\hline Total participants & $1922(100)$ & $4546(100)$ & $493(100)$ & $344(100)$ & $7305(100)$ \\
\hline Returned undelivered ${ }^{\star} \dagger$ & $593(30.9)$ & $871(19.2)$ & $52(10.5)$ & $57(16.6)$ & $1573(21.5)$ \\
\hline \multicolumn{6}{|l|}{ Returned as long term sick, maternity leave, } \\
\hline or died* & $15(0.8)$ & $4(0.1)$ & $1(0.2)$ & $0(-)$ & $20(0.3)$ \\
\hline Total delivered & $1314(100)$ & $3671(100)$ & $440(100)$ & $287(100)$ & $5712(100)$ \\
\hline Returned completed & $1019(77.5)$ & $1692(46.1)$ & $285(64.8)$ & $114(39.7)$ & $3110(54.5)$ \\
\hline Refusal & $54(4.1)$ & $74(2.0)$ & $13(3.0)$ & $9(3.1)$ & $150(2.6)$ \\
\hline Not returned & $241(18.3)$ & $1905(51.9)$ & $142(32.2)$ & $164(57.1)$ & $2452(42.9)$ \\
\hline
\end{tabular}

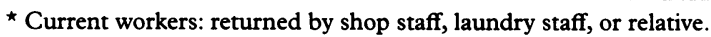

$\dagger$ Past workers: returned by post office or current occupier.

cleaning and laundry workers the completion rates were $77.5 \%$ and $64.8 \%$ respectively, whereas for past workers they were only $46.1 \%$ and $39.7 \%$ respectively. Possible reasons for the poor past worker response include change of address and inadvertent inclusion of temporary workers in this group. The age distribution of non-responders was similar to that of responders.

\section{CHARACTERISTICS OF STUDY PARTICIPANTS AND} THEIR PREGNANCIES

Table 2 shows the characteristics of the 3110 participants who returned a completed questionnaire. Although there are no significant differences between the exposure groups for age at the time of survey, two patterns are evident: dry cleaning shop workers have a younger age distribution than laundry workers and past workers have a younger age distribution than current workers.

Overall, 1748 (56.5\%) women reported having at least one pregnancy, but the proportion varied significantly $(p=0.006)$ according to type of work and current or past worker status. The lowest proportion of gravid women was in the group who were currently employed in dry cleaning shops $(51.8 \%)$, and the highest proportion was in the group of past laundry employees $(67.5 \%)$.

Of the 1748 women reporting at least one pregnancy $1643(94 \%)$ had had a liveborn child, and this proportion was similar in all groups except the current laundry workers, for whom the proportion was comparatively low at $87 \%(p=0.03)$. Of women reporting at least one pregnancy $23 \%$ had had a fetal loss or ectopic pregnancy, and this proportion did not vary between the groups. Overall, about $7 \%$ of respondents reported consulting their doctor about infertility, and this proportion did not vary greatly by employment group at the time of the survey.

\section{VALIDATION OF REPORTED SPONTANEOUS} ABORTION

The 114 women who reported a spontaneous abortion in a pregnancy exposed to either laundry or dry cleaning work and 58 women who reported a fetal loss in a pregnancy with no exposure to laundry or dry cleaning work were followed up. These women were contacted by letter and asked for details of their GP and permission to access medical records of the event. Ninety three (54\%) replied, and of these 71 gave permission to consult their GP. Sixty six of the 71 GPs (93\%) replied to our letter, and of these 59 had adequate records to confirm details of the fetal death.

There were no significant differences in the distribution of reported exposures during pregnancy in the validated and unvalidated fetal losses, and the distribution of gestational age and maternal characteristics were similar. As a result of the validation exercise, only one case was excluded from the analysis and this was a spontaneous abortion with very low gestational age reported by a dry cleaning operator.

\section{PREGNANCY OUTCOME BY EXPOSURE DURING} PREGNANCY

Table 3 shows details of the individual pregnancies according to the place and type of work of the 1748 women during each pregnancy or in the three months before concep-

Table 2 Characteristics of responders $(n(\%))$ by employment status at time of survey

\begin{tabular}{|c|c|c|c|c|c|}
\hline & \multicolumn{2}{|c|}{ Dry cleaning shop } & \multicolumn{2}{|l|}{ Laundry } & \multirow[b]{2}{*}{ Total } \\
\hline & $\begin{array}{l}\text { Current } \\
\text { worker }\end{array}$ & $\begin{array}{l}\text { Past } \\
\text { worker }\end{array}$ & $\begin{array}{l}\text { Current } \\
\text { worker }\end{array}$ & $\begin{array}{l}\text { Past } \\
\text { worker }\end{array}$ & \\
\hline $\begin{array}{l}\text { Responders } \\
\text { Age of respondent at time of survey: }\end{array}$ & $1015(100)$ & $1692(100)$ & $271(100)$ & $114(100)$ & $3092(1004)$ \\
\hline $16-20$ & $69(6.8)$ & $69(4.1)$ & $9(3.3)$ & $5(4.4)$ & $152(4.9)$ \\
\hline $21-24$ & $192(18.9)$ & $560(33.1)$ & $23(8.5)$ & $18(15.8)$ & $793(25.6)$ \\
\hline $25-29$ & $222(21.9)$ & $340(20.1)$ & $59(21.8)$ & $31(27.2)$ & $652(21.1)$ \\
\hline $30-34$ & $164(16.2)$ & $232(13.7)$ & $60(22.1)$ & $26(22.8)$ & $482(15.6)$ \\
\hline $35-39$ & $156(15.4)$ & $196(11.6)$ & $51(18.8)$ & $17(14.9)$ & $420(13.6)$ \\
\hline $40-45$ & $212(20.9)$ & $295(17.4)$ & $69(25.5)$ & $17(14.9)$ & $593(19.2)$ \\
\hline At least one pregnancy & $526(51.8)$ & $987(58.3)$ & $158(58.3)$ & $77(67.5)$ & $1748(56.5)$ \\
\hline At least one live born child & $500(49.3)$ & $923(55.1)$ & $138(50.9)$ & $73(64.0)$ & $1643(53.1)$ \\
\hline At least one fetal death or ectopic pregnancy & $112(11.0)$ & 235 (13.9) & 35 (12.9) & $16(14.0)$ & $398(12.9)$ \\
\hline Ever consulted doctor about infertility & $58(5.7)$ & $122(7.2)$ & $17(6.3)$ & $6(5.3)$ & $203(6.6)$ \\
\hline
\end{tabular}

* The forms from 18 respondents were incomplete or unreadable: data excluded from analysis. 
Table 3 Outcome of pregnancies ( $n(\%)$ ) by place and type of work at time of pregnancy or three months before conception

\begin{tabular}{|c|c|c|c|c|c|c|}
\hline & \multirow{2}{*}{$\begin{array}{l}\text { Not laundry or } \\
\text { dry cleaning* }\end{array}$} & \multirow{2}{*}{ Laundry } & \multicolumn{3}{|c|}{ Dry cleaning shop } & \multirow{2}{*}{$\begin{array}{l}\text { All types of } \\
\text { work }\end{array}$} \\
\hline & & & Non-operator & Operator & Allt & \\
\hline $\begin{array}{l}\text { Total reported pregnancies } \\
\text { Pregnancy with one or more }\end{array}$ & $2691(100)$ & $143(100)$ & $262(100)$ & $408(100)$ & $683(100)$ & $3517(100)$ \\
\hline livebirths $\ddagger$ & $2263(84.1)$ & $114(79.7)$ & $220(84.0)$ & $312(76.5)$ & $544(79.6)$ & $2921(83.1)$ \\
\hline Fetal deaths $<20$ weeks $\neq$ & $245(9.1)$ & $17(11.9)$ & $29(11.1)$ & $61(15.0)$ & $91(13.3)$ & $353(10.0)$ \\
\hline Fetal deaths $20-28$ weeks $\ddagger$ & $34(1.3)$ & $1(0.7)$ & $0(-)$ & $4(1.0)$ & $4(0.6)$ & $39(1.1)$ \\
\hline Fetal deaths $\geqslant 28$ weeks $\ddagger$ & $23(0.9)$ & $2(1.4)$ & $2(0.8)$ & $3(0.7)$ & $5(0.7)$ & $30(0.9)$ \\
\hline Ectopic pregnancy & $23(0.9)$ & $2(1.4)$ & $1(0.4)$ & $7(1.7)$ & $8(1.2)$ & $33(0.9)$ \\
\hline Hydatidiform mole & $1(0.04)$ & $0(-)$ & $0(-)$ & $0(-)$ & $0(-)$ & $1(0.03)$ \\
\hline Medical termination of pregnancy & $102(3.8)$ & $7(4.9)$ & $10(3.8)$ & $21(5.1)$ & $31(4.5)$ & $140(5.0)$ \\
\hline
\end{tabular}

* Place and type of work (if any) not known, but not working in a dry cleaning shop or a laundry at any time during the pregnancy or three months before conception.

† Operator status not known for 13 pregnancies.

$\ddagger$ Live births and fetal deaths included once if multiple pregnancy.

tion. Overall, the proportions of the different pregnancy outcomes are similar to findings from other studies: $83.1 \%$ were live births; $11.1 \%$ were fetal deaths up to 28 weeks gestation; $0.9 \%$ were late fetal deaths or stillbirths (gestation 28 weeks or more; $1 \%$ were other rarer adverse events (ectopic pregnancy, hydatidiform mole); and $5 \%$ were medical terminations.

Of the 3517 reported pregnancies, 683 (19\%) were exposed to dry cleaning work of some kind, 143 (4\%) to laundry work, and $2691(77 \%)$ were not exposed to either dry cleaning or laundry work. Interpretation of table 3 is not straightforward as each woman is counted in the table as many times as she has pregnancies. Also, an individual woman's pregnancies are not necessarily confined to one group. Although there is little overlap between women in the laundry and dry cleaning category, earlier and later pregnancies of both groups are included in the not exposed to laundry or dry cleaning group. Tables 4-6 show data for four groups of pregnancies: all reported pregnancies, pregnancies ending between 1980 and 1995, first pregnancies only, and last pregnancies only.

Table 4 shows proportions of spontaneous abortion by work group. For all work groups the proportions are higher within the subset of pregnancies ending in 1980-95, and lowest within last pregnancies. Comparing across the three main work groups the proportions are consistently higher for pregnancies occurring to women working in dry cleaning shops, lower for those working in laundries, and lowest for those occurring to women who were not working at the time in the laundry or dry cleaning industry. Within the dry cleaning group, pregnancies of women working as operators were more likely to end in a spontaneous abortion than those of women who were not operators. Within the group of unexposed pregnancies the risk of spontaneous abortion was similar for pregnancies ending before the first exposure to dry cleaning or laundry work and those ending after the last exposure to dry cleaning or laundry work.

Table 5 shows estimates of the relative risk of spontaneous abortion in pregnancies exposed to dry cleaning work compared with laundry work, and for pregnancies in dry cleaning operators versus non-operators. Pregnancies of dry cleaners as a whole did not show increased risks compared with pregnancies in laundry workers. But when pregnancies of dry cleaning operators were compared with dry cleaning non-operators, excess risks were clear. For pregnancies ending in the period 1980-95 the difference between the groups reached conventional significance $(p=0.04$, two tailed), with a $63 \%$ higher risk after taking into account differences between the groups in age at pregnancy, year of outcome, and pregnancy order. For first pregnancies only, the risk was $51 \%$ higher, and for last pregnancies $\mathbf{7 2} \%$ higher, but the $95 \%$ CIs were wide and included unity. Compared with pregnancies with no reported exposure to either laundry or dry cleaning work and ending before any exposure to laundry or dry cleaning, a similar increased risk in the dry cleaning operator group occurred (adjusted

Table 4 Risk of spontaneous abortion $(n(\%)) *$ by place and type of work at time of pregnancy or three months before conception

\begin{tabular}{|c|c|c|c|c|c|c|c|}
\hline & \multicolumn{3}{|c|}{ Not laundry or dry cleaningt } & \multirow[b]{3}{*}{ Laundry } & \multirow{2}{*}{\multicolumn{3}{|c|}{ Dry cleaning }} \\
\hline & \multirow{2}{*}{$\begin{array}{l}\text { Pregnancies before } \\
\text { first exposure to } \\
\text { laundry or dry } \\
\text { cleaning }\end{array}$} & \multirow{2}{*}{$\begin{array}{l}\text { Pregnancies after } \\
\text { last exposure to } \\
\text { laundry or dry } \\
\text { cleaning }\end{array}$} & \multirow[b]{2}{*}{$A l l$} & & & & \\
\hline & & & & & Non-operator & Operator & All \\
\hline $\begin{array}{l}\text { All reported } \\
\text { pregnancies } \\
\text { Pregnancies ending }\end{array}$ & $250(10.8)$ & $29(11.8)$ & $279(10.9)$ & $18(13.4)$ & $29(11.6)$ & $65(17.1)$ & $95(14.8)$ \\
\hline $\begin{array}{l}1980-95 \\
\text { First pregnancies } \\
\text { Last pregnancies }\end{array}$ & $185(13.5)$ & $29(13.6)$ & $\begin{array}{l}214(13.5) \\
91(8.2) \\
74(6.3)\end{array}$ & $\begin{array}{c}18(15.5) \\
9(11.0) \\
4(6.5)\end{array}$ & $\begin{array}{c}28(12.3) \\
16(11.2) \\
8(6.0)\end{array}$ & $\begin{array}{l}64(17.9) \\
39(16.1) \\
21(9.9)\end{array}$ & $\begin{array}{l}93(15.6) \\
56(14.2) \\
29(8.2)\end{array}$ \\
\hline
\end{tabular}

* Number of reported fetal losses $<28$ weeks gestation and percentage of fetal loss $<28$ weeks gestation/total livebirths and fetal deaths. † Place and type of work (if any) not known, but not working in a dry cleaning shop or a laundry at any time during the pregnancy or three months before conception.

‡ Operator status not known for 13 pregnancies. 
Table 5 Unadjusted and adjusted ORs (95\% CIs) of spontaneous abortion by place and type of work during pregnancy or three months before conception

\begin{tabular}{|c|c|c|}
\hline & Dry cleaningt v laundry & $\begin{array}{l}\text { Dry cleaing operator } v \\
\text { non-operator }\end{array}$ \\
\hline \multicolumn{3}{|c|}{ Pregnancies completed 1980-95: } \\
\hline Risk ratio & 1.01 & 1.45 \\
\hline Unadjusted OR (95\% CI) & $1.01(0.58$ to 1.75$)$ & $1.54(0.95$ to 2.50$)$ \\
\hline Adjusted OR (95\% CI) $\ddagger$ & $0.97(0.55$ to 1.69$)$ & $1.63(1.01 \text { to } 2.66)^{\star}$ \\
\hline \multicolumn{3}{|l|}{ First pregnancies: } \\
\hline Risk ratio & 1.29 & 1.44 \\
\hline Unadjusted OR (95\% CI) & $1.34(0.64$ to 2.83$)$ & $1.52(0.82$ to 2.84$)$ \\
\hline Adjusted OR (95\% CI) & $1.03(0.48$ to 2.21$)$ & $1.51(0.81$ to 2.84$)$ \\
\hline \multicolumn{3}{|l|}{ Last pregnancies: } \\
\hline Risk ratio & 1.28 & 1.65 \\
\hline Unadjusted OR (95\% CI) & $1.30(0.44$ to 3.84$)$ & $1.72(0.74$ to 4.00$)$ \\
\hline Adjusted OR $(95 \% \mathrm{CI}) \oint$ & $1.28(0.43$ to 3.81$)$ & $1.72(0.74$ to 4.01$)$ \\
\hline
\end{tabular}

$\star \mathrm{p}=0.04$.

† Operators, non-operators, and those for whom operator status not known.

$\ddagger$ Adjusted for maternal age, pregnancy order, and year of birth.

$\checkmark$ Adjusted for maternal age and year of birth.

Table 6 Risk and ORs (95\% CIs) of spontaneous abortion in pregnancies exposed to dry cleaning and laundry work $v$ unexposed $\neq$ pregnancies

\begin{tabular}{|c|c|c|c|}
\hline Pregnancies completed 1980-95 & Laundry & $\begin{array}{l}\text { Dry cleaning } \\
\text { non-operators }\end{array}$ & Dry cleaning operators \\
\hline \multicolumn{4}{|l|}{$\begin{array}{l}\text { Pregnancies before first } \\
\text { exposed pregnancy as } \\
\text { control: }\end{array}$} \\
\hline Risk ratio & 1.15 & 0.91 & 1.33 \\
\hline Unadjusted OR ( $95 \% \mathrm{CI})$ & $1.18(0.69$ to 1.99$)$ & $0.90(0.59$ to 1.38$)$ & $1.38(1.01$ to 1.89$)$ \\
\hline Adjusted OR $(95 \%$ CI $) \subseteq$ & $1.49(0.87$ to 2.58$)$ & $1.02(0.65$ to 1.60$)$ & $1.67(1.17 \text { to } 2.36)^{\star}$ \\
\hline \multicolumn{4}{|l|}{$\begin{array}{l}\text { Pregnancies after last } \\
\text { exposed pregnancy as } \\
\text { control: }\end{array}$} \\
\hline Risk ratio & 1.14 & 0.90 & 1.31 \\
\hline Unadjusted OR (95\% CI) & $1.18(0.63$ to 2.21$)$ & $0.90(0.52$ to 1.55$)$ & $1.39(0.87$ to 2.21$)$ \\
\hline Adjusted OR (95\% CI) & $1.48(0.76$ to 2.86$)$ & $1.11(0.62$ to 1.99$)$ & $1.82(1.09$ to 3.05$) \dagger$ \\
\hline
\end{tabular}

${ }^{\star} p=0.004 ; \mathrm{p}=0.022$

$\ddagger$ Place and type of work (if any) not known, but not working in a dry cleaning shop or a laundry at any time during the pregnancy or three months before conception.

$\uparrow$ Adjusted for maternal age, pregnancy order, and year of birth.

odds ratio $=1.67, p=0.004$, table 6 ). With unexposed pregnancies ending after the last exposed pregnancy as the comparison group, a significant adjusted odds ratio of 1.82 $(p=0.022)$ resulted (table 6$)$. When similar comparisons were made for non-operators and laundry workers, no excess risks were found.

\section{Discussion}

The study described here was set up to examine pregnancy outcome among women of reproductive age who had at some time worked in the dry cleaning or laundry industry. The response rate varied considerably by type of employee. For current employees of dry cleaning shops the response among those thought to have received a questionnaire was respectable at $81.6 \%$, with $77.5 \%$ of questionnaires being returned complete and $4.1 \%$ returned as refusals. The response for current employees of laundry units was lower at $67.8 \%$. The difference between the two response rates might be explained by the subject matter of the survey; although the importance of the laundry group response was emphasised explicitly in the questionnaire and accompanying leaflet, some laundry workers may have considered the study irrelevant to them. For past workers the response was considerably lower than that for current employees, being $48.1 \%$ for past employees of dry cleaning shops and $42.8 \%$ for past employees of laundry units. Some of this low response might be explained by out of date home address information, as this was taken from employer records. Although $19.2 \%$ of the letters sent to past dry cleaning shop workers and $16.6 \%$ sent to past laundry workers were returned by the post office, the actual proportion of undelivered letters is likely to have been much higher as not all residents return mail addressed to previous occupiers. Further evidence of mobility in this group of workers is evident from the high proportion of staff thought to have been current employees who had already left the industry by the time of survey: $30.9 \%$ for dry cleaning shops and $10.5 \%$ for laundry units.

Of the total 3517 pregnancies reported by study participants $683(19 \%)$ occurred in women who were employed in a drying cleaning shop during the pregnancy or in the three months before its conception: $408(12 \%)$ were to operators and $262(7 \%)$ to non-operators. Of the remaining pregnancies, $143(4 \%)$ occurred in laundry workers and 2691 (77\%) occurred when the women were not employed in the dry cleaning or laundry industry. One of the original aims had been to recruit enough laundry workers into the study to allow a useful comparison between the reproductive outcomes of laundry and dry cleaning workers as a whole, as the physical nature of the work undertaken in the two occupations was considered similar enough to make laundry work an ideal comparison exposure in the study. In the event, the number of pregnancies occurring to women when they were employed in laundry work was disappointingly low, and, despite strenuous efforts, insufficient numbers for detailed analyses were recruited. Nevertheless, broad comparisons between the various exposure groups were possible, and the numbers of operators and non-operators within the dry cleaning industry were large enough to permit meaningful comparisons to be made.

The overall proportions of pregnancies reported as ending in stillbirth, miscarriage, induced abortion, or spontaneous abortion were generally in line with other similar surveys. $^{1-111415}$ Also, with the exception of spontaneous abortion, there were no notable differences between the various exposure groups. The proportion of pregnancies ending in spontaneous abortion varied with exposure: being lowest in unexposed pregnancies (neither dry cleaning nor laundry work) at $10.9 \%$, higher in pregnancies exposed to laundry work at $13.4 \%$, and higher still in the dry cleaning group as a whole at $14.8 \%$. Within the dry cleaning pregnancies, operators reported the highest risks: for the period 1980-95, the proportion being $17.9 \%$, with a corresponding adjusted odds ratio for operators versus non-operators of 1.63 (95\% CI 1.01 to 2.66 ). Examination of the data restricted to first and last pregnancies yielded similar risk estimates. With the larger group of unexposed pregnancies ending before any exposure to laundry or dry cleaning work as the comparison group resulted in a similar significant excess risk for dry cleaning operators, but not for dry cleaning non-operators (table 6). 
In any epidemiological investigation the possibility of bias must be considered as an explanation of the results. From the leaflet and form sent to participants, it was clear that the study was investigating the outcome of pregnancies exposed to dry cleaning work. It is thus possible that participants were more likely to return the form if they had an adverse event during such work, or remember a spontaneous abortion as occurring during such work. Contacting the GPs of a sample of women confirmed that self report of fetal loss was reliable in this group of women, and overall the reproductive patterns within these workforces were not atypical of women of a similar age in the general population. This argues against biased recall of reproductive outcome. But there may be biased recall of exposure. To explain the excess risk in the pregnancies of operators compared with non-operators an awareness of risk associated with operator status must be postulated. Before the onset of the study in 1995, the company circulated a letter to all employees explaining that our study was about to begin and suggesting that pregnant women should, in the future, avoid operator work as a "precautionary" measure. Although this letter may have raised awareness of a possible association between miscarriage and operator work, not all employees saw it, and verbal and written comments made by study participants to us did not indicate a clear perception of differential risk between the two jobs. Although we cannot be certain that women who had had a spontaneous abortion were not prone to exaggerate their exposure, it seems unlikely that this could explain all of the effect as the question about operator status was very specific, and the rate of spontaneous abortion in women who reported that they were not operators, at $11.6 \%$, was not low.

The direction and magnitude of these results is supported by other publications. ${ }^{6}{ }^{10}$ In the combined analysis of Scandinavian data, ${ }^{6}$ exposure to perchloroethylene estimated as low was associated with only a slightly increased risk compared with the risk in those with no exposure $(1.17 ; 95 \%$ CI 0.74 to 1.85$)$, but high exposure was associated with a higher excess risk $(2.88 ; 95 \%$ CI 0.98 to 8.44$)$. The Californian case-control study ${ }^{10}$ found a significant excess risk associated with exposure to perchloroethylene $(4.7 ; 95 \% \mathrm{CI} 1.1$ to 21.1$)$, with some evidence of a dose-response trend with estimated hours of exposure. These studies, taken together with the results of the present investigation, suggest that the risk of spontaneous abortion may be increased for higher levels of exposure to perchloroethylene, but not for lower levels. Most exposure classifications are, however, indirect and based on proxy measures such as job description or estimated hours of work. In the present study the proxy measure is operator versus non-operator. That this is a sensible surrogate for exposure to perchloroethylene is supported by data from a recent air sampling study within commercial dry cleaning units which confirmed that tasks involving loading and unloading the machine and cleaning button traps are often associated with considerably higher doses than jobs entailing finishing processes such as folding and pressing. ${ }^{16}$ Although there may be some sharing of tasks within small dry cleaning shops it is likely that operators, who do more of the machine based work than non-operators, would experience higher doses than nonoperators. As a differential risk of spontaneous abortion within the dry cleaning occupation has been found, we recommend further work to investigate exposure to perchloroethylene by job task as well as by job title.

We are grateful to the many women who participated in this study and to the company for allowing us to contact their employees. We particularly thank Mr Martin Gregson for his employees. We particularly thank Mr Martin Gregson for his cooperation and support throughout. We also thank Diane Deciacco and Joanne North for their clerical help on the study
and Graham Davies for setting up the database management and Graham Davies for setting up the database management
programs. The study was funded by the Health and Safety Executive.

1 Hemminki K, Franssila E, Vainio H. Spontaneous abortion among female chemical workers in Finland. Int Arch Occup Environ Health 1980;45:123-6.

2 Lindbolm ML, Hemminki K, Kyyronen P. Parental occupational exposure and spontaneous abortion in Finland. $A m$ Epidemiology 1984;120:370-8.

3 Hemminki K, Saliniemi I, Luoma K, et al. Transplacental carcinogens and mutagens: childhood cancer, malformations and abortions as risk indicators. $f$ Toxicol Environ tions and abortions as

4 Hemminki K, Lindbolm ML, Hemminki E, et al. Reproductive hazards and plastics industry. In: Jaervisalo J, ed tive hazards and plastics industry. In: Jaervisalo J, ed. Industrial hazards of plastics

5 Kyyronen P, Taskinen H, Lindbolm ML, et al. Spontaneous abortion and congenital malformations among women exposed to tetrachloroethylene in dry cleaning. $\mathcal{F}$ Epidemio Community Health 1989;43:346-51.

6 Olsen J, Hemminki K, Ahlborg G, et al. Low birthweight, congenital malformations among dry-cleaning workers in

7 Bosco MG, Figa-Talamanca I, Salerno S. Health and reproductive status of female workers in dry cleaning shops. Int ductive status of female workers in dry clean

8 Windham G, Shusterman D, Swan S, et al. Exposure to organic solvents and adverse pregnancy outcome. $A m \mathcal{f}$ Ind Med 1991;20:241-59.

$9 \mathrm{McDonald} \mathrm{AD,} \mathrm{McDonald} \mathrm{JC,} \mathrm{Armstrong} \mathrm{B,} \mathrm{et} \mathrm{al.} \mathrm{Occupa-}$ tion and pregnancy outcome. Br $\mathcal{F}$ Ind Med 1987;44:521-6.

$10 \mathrm{McDonald} \mathrm{AD}$, Armstrong B, Cherry $\mathrm{N}$, et al. Spontaneous abortion and occupation. $\mathcal{F}$ Occup Med 1986;28:1232-8.

11 Roman E, Doyle P, Ansell P, et al. Health of children born to medical radiographers. Occup Environ Med 1996;53:73-9

12 Breslow NE, Day NE. Statistical methods in cancer research. Vol 1. The analysis of case-control studies. Lyons: International Vol 1. The analysis of case-control studies. Lyons: International
Agency for Research on Cancer, 1980. (IARC Sci Publ No 82.)

13 STATACORP. Stata Statistical Software: release 5.0. College Station, Texas: Stata Corporation, 1997.

14 Wong HOC, Daling J, Cates W, et al. The epidemiology of ectopic pregnancy. Epidemiol Rev 1987;9:70-94.

15 Office of Population Censuses and Surveys. Cancer statistics 1985. London: OPCS, 1985. (OPCS Series MB 1 No 18.)

16 Edmondson GK, Palin MJ . Occupational exposure to perchloroethylene in the dry-cleaning industry in the $\mathrm{UK}$ (mono- 